\title{
REVIEW ARTICLE Tip of the iceberg: erectile dysfunction and COVID-19
}

\author{
Mehmet Kaynar ${ }^{1}$, Ana Luísa Quinta Gomes ${ }^{2}$, loannis Sokolakis (iD ${ }^{3}$ and Murat Gül (D) ${ }^{1 凶}$ \\ (c) The Author(s), under exclusive licence to Springer Nature Limited 2022
}

The novel severe acute respiratory syndrome coronavirus 2 caused the coronavirus 2019 (COVID-19) pandemic that resulted in more than 150 million infections and 3.5 million deaths globally. COVID-19 affected men more than women, emerging with more severe disease and higher mortality rates. Androgens may be responsible for the underlying reason of more severe disease, as androgen receptors have been implicated to mediate viral cell entry and infection. Besides, male reproductive organs have been reported to be affected by the especially severe disease, resulting in erectile dysfunction (ED). In this narrative review, we aimed to gather possible mechanisms of the development of ED led by COVID-19. Current evidence illuminates endothelial dysfunction, direct testicular damage, and the psychological burden of COVID-19 that are of the pathways of ED. Although the proposed underlying mechanisms partly fail to answer the questions by which COVID-19 leads to ED, it is important to monitor men who recovered from COVID-19 regarding the sexual dysfunction sequelae of infection and address the long-term consequences.

IJIR: Your Sexual Medicine Journal (2022) 34:152-157; https://doi.org/10.1038/s41443-022-00540-0

\section{INTRODUCTION}

The severe acute respiratory syndrome coronavirus 2 (SARS-CoV-2) labeled as the coronavirus disease (COVID-19) broke out in Wuhan, China in December 2019 [1]. COVID-19 outbreak has become a pandemic with an impact on all social and economic activities throughout the world due to the high mortality rates threatening the global public health with even catastrophic influence felt worldwide. This unprecedented condition for mankind made the World Health Organization (WHO) declare the virus as a pandemic on March 11, 2020 [2].

Although COVID-19 impacts all age groups, it is more prevalent in male patients with fatal outcomes in cases with comorbidities such as hypertension, diabetes, and obesity [3, 4]. The SARS-CoV2-driven immune-inflammatory responses such as cytokine storm and microvascular thrombo-embolic events leading to pulmonary and cardiovascular system-related critical clinical manifestation might be the tip of the iceberg, with potentially multi-organ dysfunction-driven clinical conditions emerging eventually $[5,6]$.

Many sexually active people facing economic and psychological pressures and COVID-19-driven health problems made it unavoidable that sexual and reproductive health would be affected in several ways. Sexually active people have experienced due to COVID-19 decreased frequency of sexual life and sexual satisfaction $[7,8]$. The pandemic of COVID-19 has disrupted relationships between partners regarding sex life and sexual function [9]. Among the complications of COVID-19, immediate or eventual, erectile dysfunction (ED), as the surrogate marker of particularly cardiovascular diseases endothelial dysfunction has been reported. The relationship between ED and COVID-19 as presented in real life is in line with the pathophysiological mechanisms connecting ED, endothelial dysfunction, and COVID-19 [10-12]. An increasing number of studies in the relevant literature make it possible to correlate primarily organic or primarily psychogenic ED with
SARS-CoV-2 infection-associated disease [11, 13-15]. This review article evaluates male sexual dysfunctions connected COVID-19 with associated endothelial dysfunction, testicular insufficiency and psychological burden.

\section{COVID-19-DRIVEN ENDOTHELIAL DYSFUNCTION AND ERECTILE DYSFUNCTION}

SARS-CoV-2 is enabled by the interplay of expressed angiotensinconverting enzyme 2 (ACE2) expressed and the transmembrane protease serine 2 (TMPRSS2) with a part of the spike protein facilitating SARS-CoV-2 docking and passage into vascular endothelium cell [16]. Recent immunohistochemical evidence-based studies show that the loss of the SARS-CoV-2-infected endothelial cells' physiological functions and emerging endothelial damage results in a thrombo-embolic change of the vascular lumen, formation of immune-thrombosis, and circulatory disorder in multiple organs. The emerging evidence show that endothelial dysfunction is a pivotal determinant of COVID-19 symptoms [17, 18]. The final and visible result of the cells coming from the endothelium taken by SARS-CoV2 is the thrombo-embolic vascular lumen change in the endothelium, the formation of immunothrombosis and the emergence of reversal in many organs. Endothelial dysfunction is a key determinant of COVID-19 symptoms [17, 18] (Fig. 1). In hospitalized COVID-19 cases, comorbidities such as hypertension, obesity, and diabetes, cardiovascular disease with underlying endothelial damage are widely evident $[19,20]$. Therefore, endothelial dysfunction is a common denominator in reported COVID-19 comorbidities. Moreover, ACE2 expression decreases with old age predicts a lower rate of SARS-CoV-2 infection in the older population [21]. The ACE2 system plays a vital role in cellular homeostasis perseveration against viral infection, specifically in COVID-19 infection and is widely distributed in the pulmonary and vascular system and

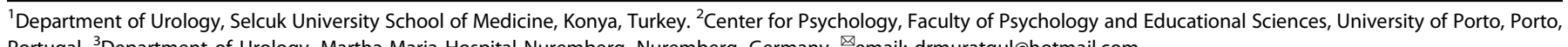
Portugal. ${ }^{3}$ Department of Urology, Martha-Maria Hospital Nuremberg, Nuremberg, Germany. ${ }^{凶}$ email: drmuratgul@hotmail.com

Received: 7 October 2021 Revised: 31 January 2022 Accepted: 2 February 2022

Published online: 12 February 2022 


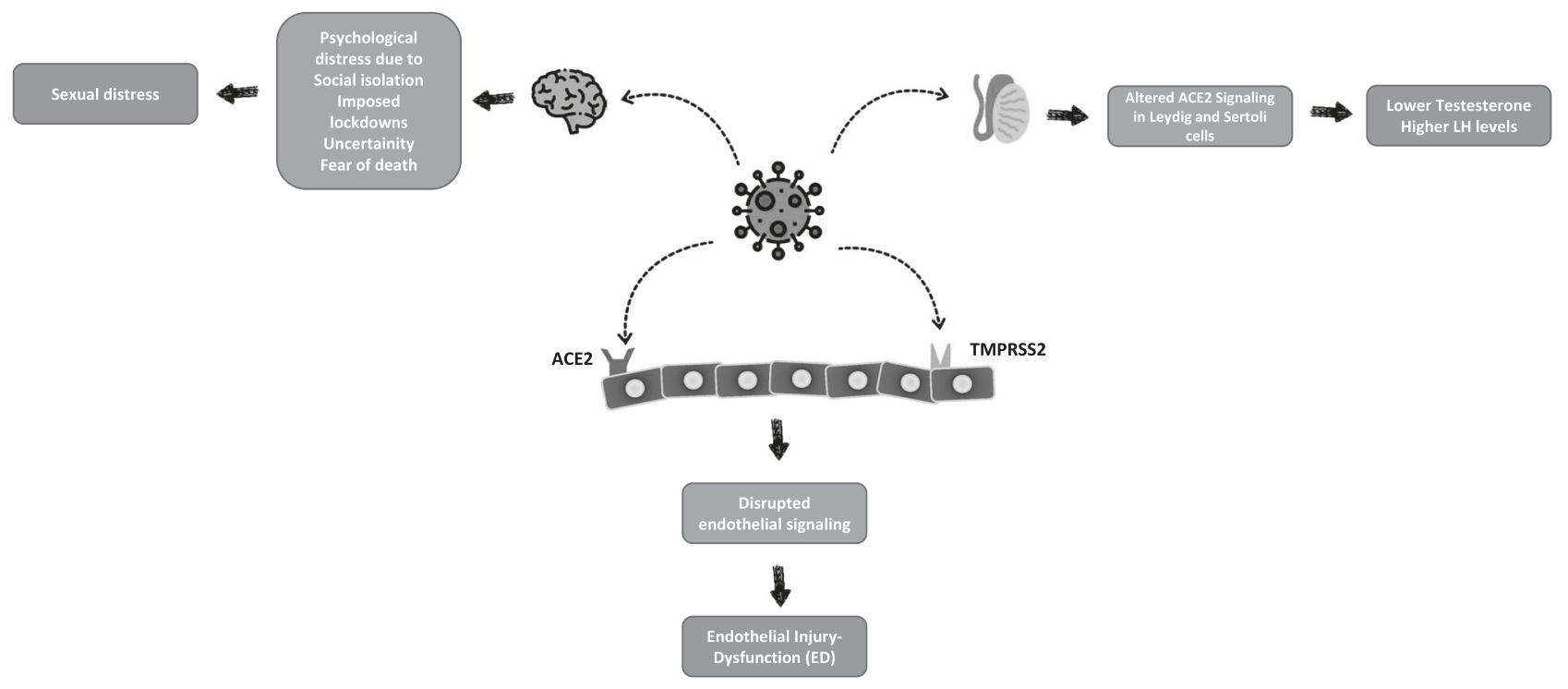

This figure has been designed using resources from Flaticon.com under free licence.

Fig. 1 Possible pathways through which COVID-19 causes erectile dysfunction. For ACE2 mediated cell entry of the SARS-CoV-2, coexpression of one more protein-Transmembrane protease serine 2 (TMPRSS2) is essential. Binding of SARS-CoV-2 to ACE2 receptor at the endothelial cell surface disrupts endothelial signaling and therefore leads to endothelial injury. In the same way, altered ACE2 signaling stemmed from SARS-CoV-2 in the testis cause malfunction in Leydig and Sertoli cells. Psychological distress due to COVID-19 risen by social isolation, imposed lockdowns, uncertainty, fear of death, etc., may cause sexual distress as well.

testicles especially in the lung, heart, kidneys and testis [22]. Endothelial dysfunction pathophysiology and damage offers insights into COVID-19-related mortality and morbidity.

Normal erectile function is a result of complex mechanisms including neural, vascular, and hormonal signaling. Impairment of psychological, neurological, hormonal, vascular, and cavernosal factors, individually, or in combination, can induce ED. Numerous pathophysiological pathways can exist together and have combined a negative impact on erectile function [23]. The underlying reason for COVID-19-driven ED could be the associations established between endothelial dysfunction and the SARSCoV-2 corrupting the physiological pathways involved in the regulation of erection. ED is associated with various causal factors such as age, diabetes mellitus, dyslipidemia, hypertension, cardiovascular disease, BMI/obesity/waist circumference, and metabolic syndrome $[23,24]$. Alongside the developments in the conception of cardiovascular physiology, the most vigorous efforts in understanding the physiology of penile erection have focused on enlightening mechanisms related to the functions of the endothelium and vascular smooth muscle of the corpus cavernosum. Endothelial cells and neurons play an active and dynamic role in the vascular smooth muscle tonus. The presence or the emergence of ED facilitates the risk of future progressive cardiovascular events, cerebrovascular events, and all-cause mortality, with an incline towards a higher risk of cardiovascular mortality [25]. Therefore, ED could be a manifestation of coronary artery and peripheral vascular disease and also as a potential indicator of cardiovascular disease $[26,27]$. The relationship of comorbidity factors, SARS-CoV-2, and vascular dysfunction/injury has been extensively reported along with the role of comorbidity factors and SARS-CoV-2 in vascular dysfunction and vascular injury. Endothelial dysfunction is related to factors such as aging, hypertension, and diabetes. SARS-CoV-2 can also cause vascular damage directly or indirectly by stimulating immune response which results in excessive cytokine production (cytokine storm) that can also lead to vascular damage [28].

On the other hand, epidemiological data also highlighted the relationship between ED and immuno-inflammatory system such as inflammatory bowel disease, kidney disease, rheumatic disease, psoriasis, gouty arthritis and ankylosing spondylitis as other potential risk factors [27]. Moreover, inflammatory cytokines such as TNF- $\alpha$, IL- 6 and IL- $1 \beta$ that occur in hyperinflammation of COVID19 have been shown to be associated with clinical progression of sexual dysfunction $[29,30]$.

A well-known fact is that nitric oxide (NO) synthesized with healthy endothelial cells is the primary mediator in the endothelium-dependent relaxation process in the corpus cavernosum. Diminished nitric oxide synthase (eNOS) expression-driven lowered NO bioavailability is the primary cause of endothelial dysfunction. Attenuation of endothelium-bound vasodilation of cavernosal tissue is present in diabetes [31]. Limited bioavailability of the endothelium-synthesized dilating molecule NO resulting from oxidative stress is the main mechanism mediating limited endothelium-dependent dilation with aging [32]. Immunohistochemical analyses have revealed suppressed endothelial eNOS expression in the corpus cavernosum of COVID-19 (+) male patients compared to non-COVID-19 (-) cases, in line with endothelial dysfunction [33].

One of the most important evidence shows the presence of viral RNA in COVID-19 $(+)$ specimen subsequent to SARS-CoV-2 viral spikes in penile vascular endothelial cells of the COVID-19 (+) patients [33]. This condition can be considered as an important notion for widespread endothelial cell dysfunction and ED. One of the delayed COVID-19-related silently growing problems seems to be ED since the penile system is covered up with endothelial rich blood vessels just as the lung, heart and kidney.

\section{THE TESTICULAR AFFINITY OF ACE2 RECEPTORS FOR SARS-} COV-2

SARS-CoV-2, the virus that causes COVID-19, can infect host cells by interacting the viral spike $(\mathrm{S})$ protein with membrane-bound ACE2 on the respiratory epithelium [34]. ACE2 receptors have been identified in various systems, including the cardiovascular, gastrointestinal, neuroendocrine, genitourinary, and respiratory systems [35]. Human testicular tissue also contains these receptors 
on both germ and somatic cells [35]. Results from the bioinformatic analysis have demonstrated that ACE2 is highly expressed in Leydig cells, seminiferous tubules, and germ cells [36]. A study also revealed that the testicular tissue has the highest concentration of ACE2 receptors compared to other human tissues, even higher than the lung tissue, which is the main target of the virus. Immunohistochemical analysis showed high ACE2 expression in sperm and Leydig cells, moderate expression in seminiferous vesicle glands, and low expression in the prostate and bladder [37]. Besides, the presence of another transmembrane protease named TMPRSS2 seems to play an essential role in the clinical infection of SARS-CoV-2. This protease assists the breakdown of the viral S protein favoring its fusion and invasion into the cell [16]. Interestingly, both ACE2 and TMPRSS2 are shown to be androgenregulated $[38,39]$. These facts all together bring up a hypothesis that the tissue of the testicles may be vulnerable to contamination by this new virus, reinforcing the importance of monitoring the testicular function in infected patients.

Current literature seems to corroborate this hypothesis. A study by $\mathrm{Ma}$ et al. [40] demonstrated lower testosterone and higher LH levels in a cohort of reproductive-aged SARS-CoV-2-infected males, compared to age-matched healthy controls [41] (Fig. 1). Rastrelli et al. showed that patients infected with SARS-CoV-2 might have decreased total and free testosterone levels, and these lower levels of testosterone levels positively correlate with disease progression [41]. Similarly, Çayan et al. showed that circulating testosterone levels decreased in patients infected with SARS-CoV2 , and lower testosterone levels were associated with mortality [42]. In another study, testosterone deficiency was found in $74 \%$ of the patients with COVID-19 compared with $38 \%$ in age-match control men [43]. A recent large case-control study demonstrated that COVID-19 is associated with lower circulation total testosterone levels and related to secondary hypogonadism in a high percentage of infected patients (85\%) [44]. We understand from this evidence that testicular damage may be a harmful consequence of the infection and may contribute to other components (endothelial dysfunction and physiological burden) causing ED.

To date, there is no definite consensus regarding COVID-19 infection and its effect on the male reproductive system. Studies regarding the presence of SARS-CoV-2 mRNA or virus in the semen or testicular tissue have shown contradictory results. Some studies report no evidence of the presence of SARS-CoV-2 in the semen or testicular tissue and on the other hand, some studies report the presence of SARS-CoV-2 in testicular tissue with clinical evidence of hypergonadotropic hypogonadism or damage to spermatogenesis $[45,46]$. As with anything new, there are more suspicions and hypotheses than certainties in terms of COVID-19 effects on the male reproductive system [36]. However, based on current knowledge, the health care system needs to consider the male reproductive system involvement in critically ill patients [47]. The hypothetical mechanisms for this damage include direct viral invasion to testicular tissue through ACE2 receptors, temperaturerelated testicular damage resulting from persistent high fever, secondary inflammatory, and autoimmune responses, and viral infection-related oxidative stress [48, 49]. Further studies are needed, including long-term follow-up of the patients after COVID-19 infection, since clinical and epidemiological evidence regarding the effects of COVID-19 on reproductive health and future infertility of male patients is scarce.

\section{THE PSYCHOLOGICAL BURDEN OF THE COVID-19 PANDEMIC AND THE ASSOCIATED RESTRICTIVE MEASURES AS RISK FACTORS FOR ED}

As an attempt to limit the spread of the SARS-CoV-2 virus, governments and policies entities across the world implemented several unprecedented restrictive measures, such as social distancing, isolation, and imposed lockdown, that have drastically altered people's lives and had a profound effect on multiple aspects of the global economy [50]. Even though such measures represented an effective strategy in controlling COVID-19 disease, they have also exposed individuals to increased psychological distress. The extent to which these measures affected the general public's mental health is yet to be known. However, the dramatic effects of social isolation and distancing measures have been extensively recognized in several areas of individuals' health and well-being [51, 52]. Along with the pervasive fear of contracting the virus, the uncertainty regarding the future, the financial, economic, and overall global losses, and the reduced social support during confinement have contributed to the experience of significant levels of psychological distress, exacerbation of worry, anxiety, and depression in individuals of the general population worldwide [52] (Fig. 1). This sudden and dramatic new reality (e.g., working from home, homeschooling, unexpected unemployment, being away from loved ones, new familiar and relationship dynamics) could also have contributed to triggering underlying mental vulnerabilities in healthy individuals and/or in reactivating psychiatric illnesses in those with pre-existing mental health conditions [52-54].

The overall sense of uncertainty and unpredictability associated with the COVID-19 pandemic and the adopted restrictive measures, along with individuals' increased levels of experienced emotional distress, also affected interpersonal and intimate relationships during this critical period and in the long term [55]. Individual's concerns related to safe intimate/sexual interactions, forced separation of intimate partners, and escalation in marital conflicts and deterioration in communication are among the most relevant contributing factors to the experience of an individual's sexual difficulties and sexual dissatisfaction during this period [56-58]. Discrepancies in sexual desire or in sexual expression and lack of privacy during confinement, have also been identified as contributing to the intensification of sexual problems and sexual distress [59]. In fact, this context of the pandemic crisis created a unique opportunity for studying the impact of adverse events in individuals' sexuality and sexual functioning, and a growing body of research has emerged over the past year as a result.

Despite the evidence indicating a paradoxical increase of sexual desire and sexual activity during this critical period in men and women $[60,61]$, possibly occurring as a strategy to cope with negative affective states and as an attempt to regulate negative emotions, most studies have been reporting on the negative effects of the COVID-19 pandemic and associated mitigating measures on sexual functioning and satisfaction [62-67]. A significant decline in male sexual function, particularly the deterioration of erectile response, has been consistently reported and identified as being strongly associated with anxiety and depressive symptoms experienced during the current pandemic crisis $[9,68]$. Accordingly, lower levels of psychological adjustment during imposed confinements were found to impact negatively erectile function, along with sexual desire, and sexual and overall satisfaction in men, above and beyond the single effects of the confinement [69]. These findings have drawn attention to the importance of conceptualizing male's sexual functioning within a contextual frame, highlighting the importance of current life stressors (e.g., critical life events) and their intersection with psychological adjustment in the modulation of male's sexuality and sexual functioning $[69,70]$.

Indeed, the context of the COVID-19 pandemic crisis has been proposed as a long-term stressor, representing a critical period with the potential to work as a precipitant factor in triggering erectile problems in men [71]. Under perceived adverse circumstances (e.g., social isolation, concerns related to finances, new family and relationship dynamics, concerns related to intimacy and the sexual partner), erectile difficulties can be 
expected to emerge (or be exacerbated if associated with a myriad of organic risk factors) as a result of the activation of individual's psychological vulnerabilities in response to increased emotional distress [71]. Along with specific dysfunctional sexual beliefs (e.g., age-related beliefs, male conservative sexual beliefs, and "macho beliefs"), personality traits such as neuroticism and extraversion have been shown to play an essential role as vulnerability factors for the development and maintenance/ exacerbation of male sexual problems [72-77]. There is recent evidence showing the relevance of neuroticism and low extraversion, as well as age-related sexual beliefs, in predicting sexual functioning and distress in men during the current COVID19 pandemic crisis.

Under such challenging contextual circumstances, sexual arousal response may be affected by cognitive interference that hinders an individual's effective processing of sexual and erotic stimuli during sexual situations, in response to the activation of a perceived internal or external threat, or anticipated negative consequences of sex (e.g., being infected with SARS-CoV-2) [78]. The inefficient cognitive processing of sexual stimuli due to cognitive distraction (e.g., distracting thoughts related to sexual performance and its consequences, fear of contagion) compromises the activation of the physiological and subjective sexual responses necessary for an adequate sexual response to occur, as well as to the experience of sexual pleasure. As a result, a decrease in sexual arousal will be inevitable and will heighten an individual's attention to performance-related concerns (excessive focus on erection loss), resulting in a cascade of negative selfappraisals associated with sexual failure and its consequences (e.g., "there's must be something wrong with me", "I won't be able to sexually satisfy my partner"), contributing to man's withdrawal of the sexual situation. The recurrent experience of an inconsistent sexual arousal response and the learned tendency to respond to failure over time will intensify an individual's negative emotions and distress and amplify anxiety-related concerns about sexual performance, contributing to the avoidance of future sexual situations [78].

In light of the current pandemic crisis scenario and its associated implications as representing a risk factor for the development/exacerbation of ED in vulnerable individuals, along with a myriad of emotional conditions, awareness for sexual and mental health has become an international public health priority [79]. Several local and international institutions (e.g., World Association for Sexual Health, WHO) have been leading specific actions to increase information, resources, and support during the pandemic crisis, in an attempt to mitigate its detrimental effects on mental and sexual health and well-being of the general population worldwide. In addition, as sexual activity and sexual satisfaction may play an essential protective role in individuals' mental health and well-being during the COVID-19 pandemic, specialized support interventions targeting overall sexual problems should be available during this period. This is particularly relevant regarding ED as it has been recently suggested as a potential long-term consequence of COVID-19, given the significant increase of self-reported erectile problems in men with previously reported SARS-CoV-2 infection [80]. Therefore, a comprehensive and effective clinical intervention for ED emerging in such a challenging context requires an integrated and multidisciplinary approach, combining biomedical and tailored psychological interventions to the patient's needs and circumstances (e.g., cognitive-behavior therapy, sex therapy). Such specialized interventions may be delivered using both the conventional form and an e-Health format [56] and should be focusing on promoting individual's and/or couple's sexual functioning and satisfaction, along with the management of concomitant medical or psychiatric conditions, not only during the current pandemic COVID-19 crisis but also in the short and long term [27, 81-83].

\section{CONCLUSION}

Most data support the role of COVID-19 in ED. Although the exact pathophysiology is not fully elucidated, we strove to gather the most probable reasons around this topic and elaborate on related mechanisms. In summary, COVID-19 infection could affect male sexual function through endothelial damage in erectile tissue, testicular damage, and psychological alterations. Long-term and well-designed studies are needed to clarify the role of COVID19 on ED.

\section{REFERENCES}

1. Zhu N, Zhang D, Wang W, Li X, Yang B, Song J, et al. A novel Coronavirus from patients with pneumonia in China, 2019. N Engl J Med. 2020;382:727-33.

2. World Health Organization. WHO Director-General's opening remarks at the media briefing on COVID-19 - 11 March 2020. 2020. https://www.who.int/ director-general/speeches/detail/who-director-general-s-opening-remarks-atthe-media-briefing-on-covid-19---11-march-2020. Accessed 17 Jan 2022

3. Cheng $\mathrm{H}$, Wang $\mathrm{Y}$, Wang GQ. Organ-protective effect of angiotensin-converting enzyme 2 and its effect on the prognosis of COVID-19. J Med Virol. 2020; 92:726-30.

4. Huang $C$, Wang $Y$, Li X, Ren L, Zhao J, Hu Y, et al. Clinical features of patients infected with 2019 novel coronavirus in Wuhan, China. Lancet. 2020;395:497-506.

5. Iba T, Connors JM, Levy JH. The coagulopathy, endotheliopathy, and vasculitis of COVID-19. Inflamm Res. 2020;69:1181-9.

6. Sun X, Wang T, Cai D, Hu Z, Chen J, Liao H, et al. Cytokine storm intervention in the early stages of COVID-19 pneumonia. Cytokine Growth Factor Rev. 2020;53: 38-42.

7. Nessaibia I, Sagese R, Atwood L, Bouslama Z, Cocci L, Merad T, et al. The way COVID-19 transforms our sexual lives. Int J Impot Res. 2021;1-3.

8. Lo SP, Hsieh TC, Pastuszak AW, Hotaling JM, Patel DP. Effects of SARS CoV-2, COVID-19, and its vaccines on male sexual health and reproduction: where do we stand? Int J Impot Res. 2021;1-7

9. Fang D, Peng J, Liao S, Tang Y, Cui W, Yuan Y, et al. An online questionnaire survey on the sexual life and sexual function of Chinese adult men during the Coronavirus Disease 2019 epidemic. Sex Med. 2021;9:100293.

10. Sansone A, Mollaioli D, Ciocca G, Colonnello E, Limoncin E, Balercia G, et al. "Mask up to keep it up": preliminary evidence of the association between erectile dysfunction and COVID-19. Andrology. 2021;9:1053-9.

11. Bakr AM, El-Sakka Al. Erectile dysfunction among patients and health care providers during COVID-19 pandemic: a systematic review. Int J Impot Res. 2022. Online ahead of print.

12. Sansone $\mathrm{A}$, Mollaioli $\mathrm{D}$, Limoncin $\mathrm{E}$, Ciocca $\mathrm{G}, \mathrm{Bắc} \mathrm{NH}, \mathrm{Cao} \mathrm{TN}$, et al. The sexual long COVID (SLC): erectile dysfunction as a biomarker of systemic complications for COVID-19 long haulers. Sex Med Rev. 2021;S2050-0521(21)00085-8.

13. Saad HM, GamalEl Din SF, Elbokl OM, Adel A. Predictive factors of erectile dysfunction in Egyptian individuals after contracting COVID-19: a prospective casecontrol study. Andrologia. 2022;54:e14308.

14. Karkin K, Alma E. Erectile dysfunction and testosterone levels prior to COVID-19 disease: what is the relationship? Arch Ital Urol Androl. 2021;93:460-4.

15. Chu KY, Nackeeran S, Horodyski L, Masterson TA, Ramasamy R. COVID-19 infection is associated with new onset erectile dysfunction: insights from a national registry. Sex Med. 2022;10:100478.

16. Hoffmann M, Kleine-Weber $H$, Schroeder S, Krüger N, Herrler T, Erichsen $S$, et al. SARS-CoV-2 cell entry depends on ACE2 and TMPRSS2 and is blocked by a clinically proven protease inhibitor. Cell. 2020;181:271. e278

17. Jung F, Krüger-Genge A, Franke RP, Hufert F, Küpper JH. COVID-19 and the endothelium. Clin Hemorheol Microcirculation. 2020;75:7-11.

18. Pons S, Fodil S, Azoulay E, Zafrani L. The vascular endothelium: the cornerstone of organ dysfunction in severe SARS-CoV-2 infection. Crit Care. 2020;24:353.

19. Yang J, Zheng Y, Gou X, Pu K, Chen Z, Guo Q, et al. Prevalence of comorbidities and its effects in patients infected with SARS-CoV-2: a systematic review and meta-analysis. Int J Infect Dis. 2020;94:91-95.

20. Richardson S, Hirsch JS, Narasimhan M, Crawford JM, McGinn T, Davidson KW, et al. Presenting characteristics, comorbidities, and outcomes among 5700 patients hospitalized with COVID-19 in the New York City Area. JAMA. 2020;323: 2052-9.

21. Yoon HE, Kim EN, Kim MY, Lim JH, Jang IA, Ban TH, et al. Age-associated changes in the vascular renin-angiotensin system in mice. Oxid Med Cell Longev. 2016; 2016:6731093.

22. Li MY, Li L, Zhang Y, Wang XS. Expression of the SARS-CoV-2 cell receptor gene ACE2 in a wide variety of human tissues. Infect Dis Poverty. 2020;9:45.

23. Gratzke C, Angulo J, Chitaley K, Dai YT, Kim NN, Paick JS, et al. Anatomy, physiology, and pathophysiology of erectile dysfunction. J Sex Med. 2010;7:445-75. 
24. Besiroglu H, Otunctemur A, Ozbek E. The relationship between metabolic syndrome, its components, and erectile dysfunction: a systematic review and a meta-analysis of observational studies. J Sex Med. 2015;12:1309-18.

25. Vlachopoulos CV, Terentes-Printzios DG, loakeimidis NK, Aznaouridis KA, Stefanadis $\mathrm{Cl}$. Prediction of cardiovascular events and all-cause mortality with erectile dysfunction: a systematic review and meta-analysis of cohort studies. Circ Cardiovasc Qual Outcomes. 2013;6:99-109.

26. Dong JY, Zhang YH, Qin LQ. Erectile dysfunction and risk of cardiovascular disease: meta-analysis of prospective cohort studies. J Am Coll Cardiol. 2011;58: 1378-85.

27. Salonia A, Bettocchi C, Boeri L, Capogrosso P, Carvalho J, Cilesiz NC, et al. European Association of Urology Guidelines on sexual and reproductive health-2021 update: male sexual dysfunction. Eur Urol. 2021;80:333-57.

28. Costa TJ, Potje SR, Fraga-Silva TFC, da Silva-Neto JA, Barros PR, Rodrigues D, et al. Mitochondrial DNA and TLR9 activation contribute to SARS-CoV-2-induced endothelial cell damage. Vasc Pharmacol. 2021;142:106946.

29. Pedersen SF, Ho YC. SARS-CoV-2: a storm is raging. J Clin Invest. 2020;130:2202-5.

30. Maiorino MI, Bellastella G, Giugliano D, Esposito K. From inflammation to sexual dysfunctions: a journey through diabetes, obesity, and metabolic syndrome. J Endocrinol Invest. 2018;41:1249-58.

31. Musicki B, Burnett AL. Endothelial dysfunction in diabetic erectile dysfunction. Int J Impot Res. 2007;19:129-38.

32. Seals DR, Jablonski KL, Donato AJ. Aging and vascular endothelial function in humans. Clin Sci. 2011;120:357-75.

33. Kresch E, Achua J, Saltzman R, Khodamoradi K, Arora H, Ibrahim E, et al. COVID-19 endothelial dysfunction can cause erectile dysfunction: histopathological, immunohistochemical, and ultrastructural study of the human penis. World J Men's Health. 2021;39:466-9.

34. Reynolds HR, Adhikari S, Pulgarin C, Troxel AB, Iturrate E, Johnson SB, et al. Reninangiotensin-aldosterone system inhibitors and risk of Covid-19. N Engl J Med. 2020;382:2441-8.

35. Li M-Y, Li L, Zhang Y, Wang X-S. Expression of the SARS-CoV-2 cell receptor gene ACE2 in a wide variety of human tissues. Infect Dis Poverty. 2020;9:1-7.

36. Gröner MF, Carvalho RCD, Camillo J, Ferreira PRA, Fraietta R. Effects of Covid-19 on male reproductive system. Int Braz J Urol. 2020;47:185-90.

37. Zhang J, Wu Y, Wang R, Lu K, Tu M, Guo H, et al. Bioinformatic analysis reveals that the reproductive system is potentially at risk from SARS-CoV-2. Preprints 2020, 2020020307

38. Kalidhindi RSR, Borkar NA, Ambhore NS, Pabelick CM, Prakash YS, Sathish V. Sex steroids skew ACE2 expression in human airway: a contributing factor to sex differences in COVID-19? Am J Physiol Lung Cell Mol Physiol. 2020;319: L843-L847.

39. Montopoli M, Zumerle S, Vettor R, Rugge $M$, Zorzi $M$, Catapano CV, et al. Androgen-deprivation therapies for prostate cancer and risk of infection by SARSCoV-2: a population-based study ( $N=4532$ ). Ann Oncol. 2020;31:1040-5.

40. Ma L, Xie W, Li D, Shi L, Ye G, Mao Y, et al. Evaluation of sex-related hormones and semen characteristics in reproductive-aged male COVID-19 patients. J Med Virol. 2021;93:456-62.

41. Rastrelli G, Di Stasi V, Inglese F, Beccaria M, Garuti M, Di Costanzo D, et al. Low testosterone levels predict clinical adverse outcomes in SARS-CoV-2 pneumonia patients. Andrology. 2021;9:88-98.

42. Çayan S, Uğuz M, Saylam B, Akbay E. Effect of serum total testosterone and its relationship with other laboratory parameters on the prognosis of coronavirus disease 2019 (COVID-19) in SARS-CoV-2 infected male patients: a cohort study. Aging Male. 2020;23:1493-503.

43. Kadihasanoglu M, Aktas S, Yardimci E, Aral H, Kadioglu A. SARS-CoV-2 pneumonia affects male reproductive hormone levels: a prospective, cohort study. J Sex Med. 2021;18:256-64

44. Salonia A, Pontillo M, Capogrosso P, Gregori S, Tassara M, Boeri L, et al. Severely low testosterone in males with COVID-19: a case-control study. Andrology. 2021;9:1043-52.

45. Ma X, Guan C, Chen R, Wang Y, Feng S, Wang R, et al. Pathological and molecular examinations of postmortem testis biopsies reveal SARS-CoV-2 infection in the testis and spermatogenesis damage in COVID-19 patients. Cell Mol Immunol. 2021;18:487-9.

46. Song C, Wang Y, Li W, Hu B, Chen G, Xia P, et al. Absence of 2019 novel coronavirus in semen and testes of COVID-19 patients. Biol Reprod. 2020;103:4-6.

47. Ardestani Zadeh A, Arab D. COVID-19 and male reproductive system: pathogenic features and possible mechanisms. J Mol Histol. 2021;52:869-78.

48. Fathi M, Vakili K, Aliaghaei A, Nematollahi S, Peirouvi T, Shalizar-Jalali A. Coronavirus disease and male fertility: a systematic review. Middle East Fertil Soc J. 2021;26:26.

49. Pavone C, Giammanco GM, Baiamonte D, Pinelli M, Bonura C, Montalbano M, et al. Italian males recovering from mild COVID-19 show no evidence of SARS-
CoV-2 in semen despite prolonged nasopharyngeal swab positivity. Int J Impot Res. 2020;32:560-2.

50. Döring N. How is the COVID-19 pandemic affecting our sexualities? An overview of the current media narratives and research hypotheses. Arch Sex Behav. 2020;49:2765-78.

51. Serafini G, Parmigiani B, Amerio A, Aguglia A, Sher L, Amore M. The psychological impact of COVID-19 on the mental health in the general population. QJM. 2020;113:531-7.

52. Xiong J, Lipsitz O, Nasri F, Lui LMW, Gill H, Phan L, et al. Impact of COVID-19 pandemic on mental health in the general population: a systematic review. J Affect Disord. 2020;277:55-64.

53. Le K, Nguyen M. The psychological burden of the COVID-19 pandemic severity. Econ Hum Biol. 2021;41:100979.

54. Burhamah W, AlKhayyat A, Oroszlányová M, AlKenane A, Almansouri A, Behbehani $\mathrm{M}$, et al. The psychological burden of the COVID-19 pandemic and associated lockdown measures: experience from 4000 participants. J Affect Disord. 2020;277:977-85.

55. De Rose AF, Chierigo F, Ambrosini F, Mantica G, Borghesi M, Suardi N, et al. Sexuality during COVID lockdown: a cross-sectional Italian study among hospital workers and their relatives. Int J Impot Res. 2021;33:131-6.

56. Carvalho J, Pascoal PM. Challenges in the practice of sexual medicine in the time of COVID-19 in Portugal. J Sex Med. 2020;17:1212-5.

57. Karagöz MA, Gül A, Borg C, Erihan İB, Uslu M, Ezer M, et al. Influence of COVID-19 pandemic on sexuality: a cross-sectional study among couples in Turkey. Int J Impot Res. 2020;33:815-23.

58. Culha MG, Demir O, Sahin O, Altunrende F. Sexual attitudes of healthcare professionals during the COVID-19 outbreak. Int J Impot Res. 2021;33:102-9.

59. de Oliveira L, Carvalho J. Women's sexual health during the pandemic of COVID-19: declines in sexual function and sexual pleasure. Curr Sex Health Rep. 2021;13:1-13.

60. Stephenson R, Chavanduka TMD, Rosso MT, Sullivan SP, Pitter RA, Hunter AS, et al. Sex in the time of COVID-19: results of an online survey of gay, bisexual and other men who have sex with men's experience of sex and HIV prevention during the US COVID-19 epidemic. AIDS Behav. 2021;25:40-48.

61. Yuksel B, Ozgor F. Effect of the COVID-19 pandemic on female sexual behavior. Int J Gynaecol Obstet. 2020;150:98-102.

62. Jacob L, Smith L, Butler L, Barnett Y, Grabovac I, McDermott D, et al. Challenges in the practice of sexual medicine in the time of COVID-19 in the United Kingdom. J Sex Med. 2020;17:1229-36.

63. Karsiyakali N, Sahin Y, Ates HA, Okucu E, Karabay E. Evaluation of the sexual functioning of individuals living in Turkey during the COVID-19 pandemic: an internet-based nationwide survey study. Sex Med. 2021;9:100279.

64. Li W, Li G, Xin C, Wang Y, Yang S. Challenges in the practice of sexual medicine in the time of COVID-19 in China. J Sex Med. 2020;17:1225-8.

65. Schiavi MC, Spina V, Zullo MA, Colagiovanni V, Luffarelli P, Rago R, et al. Love in the time of COVID-19: sexual function and quality of life analysis during the social distancing measures in a group of Italian reproductive-age women. J Sex Med. 2020;17:1407-13.

66. Zattoni F, Gül M, Soligo M, Morlacco A, Motterle G, Collavino J, et al. The impact of COVID-19 pandemic on pornography habits: a global analysis of Google Trends. Int J Impot Res. 2020;33:824-31.

67. Cocci A, Presicce F, Russo Gl, Cacciamani G, Cimino S, Minervini A. How sexual medicine is facing the outbreak of COVID-19: experience of Italian urological community and future perspectives. Int J Impot Res. 2020;32:480-2.

68. Malik J, Younus F, Iftikhar I, Usman M. Love in the time of COVID-19: a scoping review on male sexual health. J Community Hosp Intern Med Perspect. 2021;11: 496-500.

69. Carvalho J, Campos P, Carrito M, Moura C, Quinta-Gomes A, Tavares I, et al. The relationship between COVID-19 confinement, psychological adjustment, and sexual functioning, in a sample of portuguese men and women. J Sex Med. 2021; 18:1191-7.

70. Pascoal PM, Carvalho J, Raposo CF, Almeida J, Beato AF. The impact of COVID-19 on sexual health: a preliminary framework based on a qualitative study with clinical sexologists. Sex Med. 2021;9:100299.

71. Nobre PJ. Psychological determinants of erectile dysfunction: testing a cognitiveemotional model. J Sex Med. 2010;7:1429-37.

72. Costa PT Jr., Fagan PJ, Piedmont RL, Ponticas Y, Wise TN. The five-factor model of personality and sexual functioning in outpatient men and women. Psychiatr Med. 1992;10:199-215.

73. Eysenck HJ. Personality and sexual adjustment. Br J Psychiatry. 1971;118:593-608.

74. Fagan PJ, Wise TN, Schmidt CW Jr., Ponticas Y, Marshall RD, Costa PT Jr. A comparison of five-factor personality dimensions in males with sexual dysfunction and males with paraphilia. J Personal Assess. 1991;57:434-48.

75. Peixoto MM, Nobre P. Personality traits, sexual problems, and sexual orientation: an empirical study. J Sex Marital Ther. 2016;42:199-213. 
76. Quinta Gomes AL, Nobre P. Personality traits and psychopathology on male sexual dysfunction: an empirical study. J Sex Med. 2011;8:461-9.

77. Rosenheim E, Neumann M. Personality characteristics of sexually dysfunctioning males and their wives. J Sex Res. 1981;17:124-38.

78. Quinta Gomes AL, Janssen E, Santos-Iglesias P, Pinto-Gouveia J, Fonseca LM, Nobre PJ. Validation of the Sexual Inhibition and Sexual Excitation Scales (SIS/ SES) in Portugal: assessing gender differences and predictors of sexual functioning. Arch Sex Behav. 2018;47:1721-32.

79. Latoo J, Haddad PM, Mistry M, Wadoo O, Islam SMS, Jan F, et al. The COVID-19 pandemic: an opportunity to make mental health a higher public health priority. BJPsych Open. 2021;7:e172.

80. Sansone A, Mollaioli D, Ciocca G, Limoncin E, Colonnello E, Vena W, et al. Addressing male sexual and reproductive health in the wake of COVID-19 outbreak. J Endocrinol Invest. 2021;44:223-31.

81. Brotto L, Atallah S, Johnson-Agbakwu C, Rosenbaum T, Abdo C, Byers ES, et al. Psychological and interpersonal dimensions of sexual function and dysfunction. J Sex Med. 2016;13:538-71.

82. Quinta Gomes AL, Nobre PJ. Depressive disorders. In: Lew-Starowicz M Giraldi A, Krüger THC, editors. Psychiatry and sexual medicine: a comprehensive guide for clinical practitioners. Cham: Springer International Publishing; 2021. p. 235-48.

83. Quinta Gomes AL, Nobre PJ. Bipolar and related disorders. In: Lew-Starowicz M, Giraldi A, Krüger THC, editors. Psychiatry and sexual medicine: a comprehensive guide for clinical practitioners. Cham: Springer International Publishing; 2021, p. 249-59.

\section{ACKNOWLEDGEMENTS}

The authors acknowledge the participants for their cooperation.

\section{AUTHOR CONTRIBUTIONS}

All authors made substantial contributions to the interpretation and reporting of the data and design and drafting of the paper. All authors provide the final approval of the paper submitted for publication and take responsibility for the accuracy and integrity of the work. MG took the lead in submitting the paper and preparing the figure.

\section{COMPETING INTERESTS}

The authors declare no competing interests.

\section{ADDITIONAL INFORMATION}

Correspondence and requests for materials should be addressed to Murat Gül.

Reprints and permission information is available at http://www.nature.com/ reprints

Publisher's note Springer Nature remains neutral with regard to jurisdictional claims in published maps and institutional affiliations. 